\title{
REVIEW
}

\section{Blood conservation strategies to reduce the need for red blood cell transfusion in critically ill patients}

\author{
Alan T. Tinmouth MD MSc, Lauralynn A. Mclntyre MD MSc, Robert A. Fowler MDCM MS
}

\section{ABSTRACT}

Anemia commonly affects critically ill patients. The causes are multifactorial and include acute blood loss, blood loss from diagnostic testing and blunted red blood cell production. Blood transfusions are frequently given to patients in intensive care units to treat low hemoglobin levels due to either acute blood loss or subacute anemia associated with critical illness. Although blood transfusion is a life-saving therapy, evidence suggests that it may be associated with an increased risk of morbidity and mortality. A number of blood conservation strategies exist that may mitigate anemia in hospital patients and limit the need for transfusion. These strategies include the use of hemostatic agents, hemoglobin substitutes and blood salvage techniques, the reduction of blood loss associated with diagnostic testing, the use of erythropoietin and the use of restrictive blood transfusion triggers. Strategies to reduce blood loss associated with diagnostic testing and the use of hemostatic agents and erythropoietin result in higher hemoglobin levels, but they have not been shown to reduce the need for blood transfusions or to improve clinical outcomes. Lowering the hemoglobin threshold at which blood is transfused will reduce the need for transfusions and is not associated with increased morbidity or mortality among most critically ill patients without active cardiac disease. Further research is needed to determine the potential roles for other blood conservation strategies.

Une version française de ce résumé est disponible à l'adresse www.cmaj.ca/cgi/content/full/I78/I/49/DCI

\section{CMAJ 2008;178(I):49-57}

A nemia commonly occurs in critically ill patients, affecting more than $90 \%$ of patients admitted to intensive care units (ICUs) by the third day. ${ }^{1}$ The reasons for anemia in critically ill patients are multifactorial and include acute blood loss (e.g., from trauma, surgery or gastrointestinal bleeding), iatrogenic blood loss from diagnostic testing and blunted red blood cell production. Many critically ill patients receive blood transfusions for the treatment of low hemoglobin levels due to either acute blood loss or subacute anemia associated with critical illness. In 2 large multicentre cohort studies, $45 \%$ of patients in ICUs in the United States ${ }^{1}$ and $37 \%$ of those in ICUs in Western Europe ${ }^{2}$ received blood transfusions.

Although blood transfusions have proven to be life-saving over nearly roo years of transfusion practice, the benefits in cases of mild to moderate anemia are still debated. ${ }^{3}$ A large body of literature documents the many potential harms associated with blood transfusions. ${ }^{4}$ In this review, we explore the rationale and summarize the evidence for blood conservation strategies to reduce acute blood loss and prevent subacute anemia in critically ill patients (Table I and Table 2). (A description of the search strategy we used to identify the studies included in this review appears in Appendix I.)

\section{Benefits and risks of blood transfusion}

Red blood cells are the main transport mechanism for oxygen delivery to the body tissues. The relation between oxygen delivery and oxygen consumption is biphasic. ${ }^{5}$ In normal physiologic states, oxygen delivery is independent of consumption, since the amount of oxygen delivered exceeds resting oxygen requirements by a factor of 2 to $4 .{ }^{6}$ However, if oxygen delivery decreases sufficiently, oxygen consumption can be limited by delivery; this point is called the anaerobic threshold. Further decreases in oxygen delivery could render tissues ischemic and contribute to multiple organ failure. A prospective study involving 2069 patients with multiple trauma showed that a worse base deficit, a surrogate measure of tissue ischemia, during the time between hospital admission and ICU admission was strongly and significantly correlated with increased in-hospital mortality ( $\mathrm{I} \% \% \mathrm{v} .45 \%$ among patients with a base deficit of $\leq 6$ v. $>6$ respectively, $p<0.000 \mathrm{I}){ }^{7}$ Red blood cells are often transfused to increase oxygen delivery and mitigate tissue ischemia; however, the ability of red blood cell transfusions to increase oxygen consumption has not been clearly demonstrated. ${ }^{6}$

Allogeneic red blood cell transfusion is associated with well-known adverse effects (Table 3) ${ }^{8,9}$ Infectious risks include possible viral, bacterial, parasitic or prion transmission. Noninfectious risks, which include febrile, allergic/anaphylactic and hemolytic transfusion reactions, transfusion-related acute lung injury (TRALI) and transfusion-associated circulatory overload (TACO), are more common than infectious risks and lead to greater morbidity and mortality. ${ }^{8}$ In addition, many observational studies and a randomized clinical trial involving

From the University of Ottawa Centre for Transfusion Research (Tinmouth, Mclntyre), Ottawa Health Research Institute, Ottawa, Ont.; the Departments of Medicine (Tinmouth) and Critical Care (Mclntyre), Ottawa Hospital, Ottawa, Ont.; and the Department of Medicine, Sunnybrook Health Sciences Centre, and the Interdepartmental Division of Critical Care, University of Toronto (Fowler), Toronto, Ont. 
critically ill patients have shown an association between blood transfusions and increased risk of infection, prolonged mechanical ventilation, multiple-organ dysfunction and death.,10 Although the exact mechanism for the increased morbidity and mortality associated with blood transfusions is unknown, immunomodulation $^{11-13}$ and the red blood cell storage lesion (decreased ability of stored red blood cells to transport, release or deliver oxygen) are plausible explanations. ${ }^{4}$

\section{Reducing acute blood loss in critically ill patients}

A number of blood conservation strategies have been used in the treatment of acute blood loss in critically ill patients (Table I and Table 2). They include the use of hemostatic agents (e.g., antifibrinolytic agents, desmopressin and re-

Table 1: Summary of clinical recommendations and evidence base for blood conservation strategies to reduce the need for blood transfusions in critically ill patients

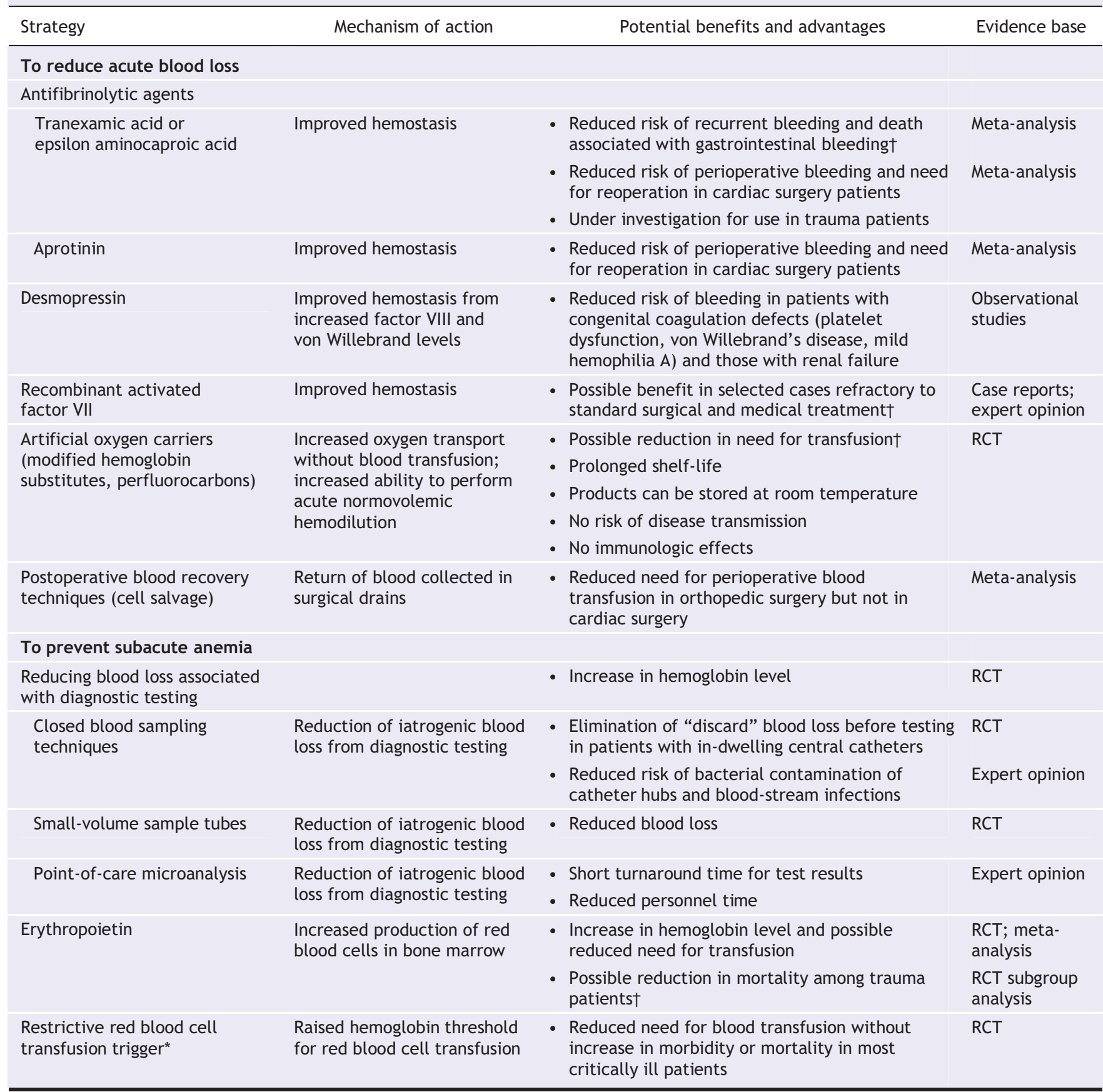

Note: $\mathrm{RCT}=$ randomized controlled trial.

*For example, a change in hemoblogin threshold for transfusion of $70 \mathrm{~g} / \mathrm{L}$.

†Further results from recent phase III randomized controlled trials are required to determine benefits and harms. 
combinant activated factor VII [recombinant factor VIIa]), artificial oxygen carriers (e.g., hemoglobin substitutes) and blood recovery techniques. These strategies are generally secondary measures that complement the primary treatment aimed at achieving hemostasis (i.e., surgery, endoscopy). Achieving surgical hemostasis is the most critical factor in stopping bleeding and reducing the need for blood transfusions. Similarly, maintenance of optimal hemostatic conditions is critical and includes the appropriate use of hemostatic blood products (platelets, frozen plasma and cryoprecipitate) and maintaining normal $\mathrm{pH}$, temperature and calcium levels. ${ }^{14}$

\section{Antifibrinolytic agents}

Antifibrinolytic agents are general hemostatic agents that inhibit the breakdown of blood clots. They are used in a variety of medical conditions to reduce bleeding. A meta-analysis of the perioperative use of antifibrinolytic agents suggested that the use of tranexamic acid, epsilon aminocaproic acid or aprotinin in selected cases can reduce the need for blood transfusions and reoperation without increasing the risk of adverse events. ${ }^{15}$ The pooled estimates suggested that aprotinin may reduce the need for blood transfusions and reoperation as compared with tranexamic acid and epsilon aminocaproic acid, but further studies are required. More recently, safety concerns associated with aprotinin have been raised. ${ }^{16,17}$ Preliminary results from a large phase III trial comparing the use of 3 antifibrinolytic agents in high-risk cardiac surgery patients suggest an increased risk of death associated with aprotinin. ${ }^{17}$ The relative effectiveness of these different agents and the potential adverse effects will be better understood when the complete results of this trial are available. The generalizability of the findings from the phase III trial for the treatment of bleeding in other critically ill patient populations is uncertain.

A systematic review of tranexamic acid for hemostasis in patients with undifferentiated upper gastrointestinal bleeding demonstrated a reduction in the recurrence of bleeding and in mortality. ${ }^{18}$ However, the incremental benefits when combined with newer endoscopic therapies and proton pump inhibitor therapy have not been evaluated.

Trauma patients may also benefit from the use of antifibrinolytic agents. Two trials ${ }^{19,20}$ evaluated the use of aprotinin in patients with trauma and traumatic brain injury; however, they were small ( $n=77$ for combined trials) and did not provide sufficient evidence to support or refute the drug's role. ${ }^{21} \mathrm{~A}$ large multicentre randomized controlled trial evaluating the effect of tranexamic acid on mortality and transfusion requirements among 20000 trauma patients at risk of hemorrhage (CRASH II study) is underway. ${ }^{22}$

On the basis of these studies, the use of antifibrinolytic agents may be useful for controlling bleeding in selected critically ill patients. However, the effectiveness of these agents in reducing transfusion requirements and the risk of thrombotic complications and death in a broad spectrum of critically ill patients remains unclear.

Table 2: Potential risks and disadvantages associated with blood conservation strategies

\begin{tabular}{|c|c|}
\hline Strategy & Potential risks and disadvantages \\
\hline Antifibrinolytic agents & $\begin{array}{l}\text { - Thrombosis } \\
\text { - Possible increased risk of death with use of aprotinin }\end{array}$ \\
\hline Desmopressin & - Thrombosis \\
\hline Recombinant activated factor VII & $\begin{array}{l}\text { - Thrombosis } \\
\text { - No benefit with routine use in cases of trauma or } \\
\text { massive bleeding }\end{array}$ \\
\hline $\begin{array}{l}\text { Artificial oxygen carriers (modified } \\
\text { hemoglobin substitutes, perfluorocarbons) }\end{array}$ & $\begin{array}{l}\text { - Short half-life } \\
\text { - Interference with laboratory measures with use } \\
\text { of hemoglobin substitutes } \\
\text { - Vasoreactivity with use of hemoglobin substitutes } \\
\text { - Use of } 100 \% \text { oxygen to provide effective oxygenation } \\
\text { with use of perfluorocarbons may cause lung injury }\end{array}$ \\
\hline $\begin{array}{l}\text { Postoperative blood recovery techniques } \\
\text { (cell salvage) }\end{array}$ & $\begin{array}{l}\text { - Limited applicability to most critical care patients } \\
\text { - Reduced quality of reinfused blood (hemolyzed, } \\
\text { diluted, cytokines [e.g., interleukins]) }\end{array}$ \\
\hline \multicolumn{2}{|l|}{$\begin{array}{l}\text { Reduction of blood loss associated } \\
\text { with diagnostic testing }\end{array}$} \\
\hline Closed blood sampling techniques & - Retrograde arterial embolization \\
\hline Small-volume sample tubes & - Potential for insufficient volume for diagnostic testing \\
\hline Point-of-care microanalysis & $\begin{array}{l}\text { - Variable accuracy and precision (need for ongoing } \\
\text { quality assurance and calibration) }\end{array}$ \\
\hline Erythropoietin & - Thrombosis \\
\hline Restrictive blood transfusion trigger & $\begin{array}{l}\text { - Possible risk of death among patients with active } \\
\text { cardiac disease }\end{array}$ \\
\hline
\end{tabular}




\section{Desmopressin}

Desmopressin acetate (I-deamino-8-D-arginine vasopressin [DDAVP]) is a synthetic analogue of arginine vasopressin. It induces the release of stored factor VIII and von Willebrand factor from endothelial cells. A dose of $0.3 \mu \mathrm{g} / \mathrm{kg}$ given subcutaneously usually results in a $3^{-}$to $5^{-}$ fold increase in levels of factor VIII and von Willebrand factor. ${ }^{23}$ For this reason, desmopressin therapy is effective in controlling and preventing bleeding in patients with mild hemophilia A and von Willebrand's disease and in patients who are hemophilia carriers. ${ }^{23}$ It has also been shown to be effective in controlling and preventing bleeding in patients who have congenital platelet disorders and those who have platelet dysfunction associated with renal failure. ${ }^{24}$ However, critically ill patients often have elevated levels of factor VIII and von Willebrand factor, both acute phase reactants, and the balance of benefits and potential harms of desmopressin for these patients is unclear. A meta-analysis of desmopressin in the treatment of perioperative bleeding showed only a small, nonsignificant reduction in blood loss without evidence of a reduction in the need for blood transfusions. ${ }^{25}$ Desmopressin therefore may not be effective in improving hemostasis or in reducing acute blood loss in critically ill patients who do not have specific bleed-

Table 3: Incidence of adverse effects associated with allogeneic red blood cell transfusions ${ }^{8}$

\begin{tabular}{|l|l|}
\hline Adverse effect & \multicolumn{1}{c}{$\begin{array}{c}\text { Incidence per } \\
\text { transfused units }\end{array}$} \\
\hline $\begin{array}{l}\text { Infectious } \\
\text { Viral infection }\end{array}$ & $1: 2000000$ \\
\hline $\begin{array}{l}\text { Hepatitis A } \\
\text { Hepatitis B }\end{array}$ & $1: 31000^{*}$ to $1: 81000 \dagger$ \\
\hline Hepatitis C & $1: 1935000$ to $1: 3100000$ \\
\hline HIV & $1: 2135000$ to $1: 4700000$ \\
\hline HTLV I/II & $1: 1900000$ \\
\hline Bacterial contamination & $1: 14000$ to $1: 28000$ \\
\hline Parasitic infection & $1: 4000000$ \\
\hline Prion disease & Rare \\
\hline Noninfectious & $1: 500$ \\
\hline Febrile nonhemolytic reaction & $1: 50$ to $1: 100$ \\
\hline Urticarial reaction & $1: 23000$ \\
\hline Anaphylactic reaction & $1: 9000$ \\
\hline Hemolytic transfusion reaction & $1: 1300$ to $1: 5000$ \\
\hline $\begin{array}{l}\text { Transfusion-related acute lung } \\
\text { injury (TRALI) }\end{array}$ & $1: 17000$ \\
\hline $\begin{array}{l}\text { Transfusion-associated } \\
\text { circulatory overload (TACO) }\end{array}$ & $1: 143000$ \\
\hline Post-transfusion purpura & \\
\hline
\end{tabular}

Note: HTLV = human T-cell lymphotrophic virus.

*Risk attributable to window of hepatitis B infection (before development of positive hepatitis $B$ surface antigen $[\mathrm{HBsAg}]$ ) and chronic carriers of hepatitis $B$ virus who have undetectable levels of HBsAg.

†Risk attributable to window of hepatitis B infection only. ing disorders such as mild hemophilia A, von Willebrand's disease and uremia.

\section{Recombinant activated factor VII}

Recombinant activated factor VII (recombinant factor VIIa) is a coagulation factor concentrate that is approved for use world wide in patients with factor deficiencies (hemophilia) and in Europe for use in patients with congenital platelet disorders. ${ }^{26}$ Numerous case reports and series have reported reduced blood loss associated with the use of recombinant factor VIIa in surgical patients, trauma patients, patients receiving massive transfusions, those with liver disease and patients with gastrointestinal bleeding. ${ }^{26} \mathrm{~A}$ few randomized controlled trials evaluating the clinical effectiveness of recombinant factor VIIa have involved critically ill patients, including patients with trauma, ${ }^{27}$ those with gastrointestinal bleeding, ${ }^{28}$ those undergoing cardiac surgery ${ }^{29}$ or liver transplantation $^{30,31}$ and patients with intracranial hemorrhage. ${ }^{32} \mathrm{~A}$ recent systematic review examined the evidence for prophylactic and therapeutic use of recombinant factor VIIa in patients without hemophilia and concluded that its effectiveness as a hemostatic agent remains uncertain. ${ }^{33}$ In that review, the pooled estimates for adverse outcomes showed nonsignificant trends for increased thromboembolic complications (relative risk I.28, 95\% confidence interval [CI] 0.84-I.95, $p=0.3$ ), cardiovascular events (relative risk 2.I8, $95 \%$ CI $0.82-5.79, p=0 . \mathrm{I}$ ) and stroke (relative risk 2.02, $95 \%$ CI $0.57-7.17, p=0.3$ ).

Boffard and colleagues ${ }^{27}$ recently published 2 parallel, multicentre randomized controlled trials that examined the use of recombinant factor VIIa versus placebo in patients with blunt ( $n=\mathrm{I} 43)$ and penetrating $(n=\mathrm{I} 34)$ trauma. Patients who received 8 units of blood were randomly assigned to receive either recombinant factor VIIa (initial dose of $200 \mu \mathrm{g} / \mathrm{kg}$ plus additional doses of Ioo $\mu \mathrm{g} / \mathrm{kg}$ I and 3 hours later) or placebo. Overall, there was no significant difference between the treatment and placebo groups in the number of units of blood subsequently transfused (primary outcome measure). Among patients who survived more than 48 hours, recombinant factor VIIa was associated with a reduction in the number of transfusions by 2.6 units ( $90 \%$ CI $0.7-4.6$, $p=0.02)$ in the blunt trauma group and by $\mathrm{I} .0$ unit (90\% CI $0.0-4.6, p=0$. Io) in the penetrating trauma group. No differences in mortality or thromboembolic events between the groups were noted, but the trial was not powered to evaluate these end points.

Bosch and colleagues ${ }^{28}$ evaluated the use of recombinant factor VIIa in a randomized controlled trial involving 245 patients with upper gastrointestinal bleeding and cirrhosis. In addition to endoscopy and standard care, patients were randomly assigned to receive either 8 doses of recombinant factor VIIa (Ioo $\mu \mathrm{g} / \mathrm{kg}$ each) or placebo over 30 hours. No differences between the 2 groups were observed in controlling bleeding within 24 hours after the first dose, the incidence of recurrent bleeding between 24 hours and day 5 , the number of blood transfusions or the number of deaths within 5 days.

Among 399 patients with intracranial hemorrhage, a phase II multicentre randomized double-blind dose-finding 
study of recombinant factor VIIa showed a reduction in mortality (overall odds ratio I.8, 95\% CI I.I-3.0, $p=0.02$ ) and in disability, using the modified Rankin score (odds ratio 2.2, $95 \%$ CI I.3-3.8, $p=0.004) .{ }^{32}$ Only patients who were seen within 4 hours after the onset of symptoms and who had a Glasgow coma score of more than 5 and no history of cardiac or thromboembolic disease were included. The investigators found a nonsignificant increase in thrombotic events among patients receiving recombinant factor VIIa. Preliminary results from another multicentre randomized controlled trial of recombinant factor VIIa involving patients with intracranial hemorrhage $(n=82 \mathrm{I})$ did not show similar benefits in reducing morbidity and mortality. ${ }^{34}$ Pending the full publication of these results, the role of recombinant factor VIIa will need to be re-evaluated.

On the basis of the studies to date, the routine use of recombinant factor VIIa in critically ill patients cannot be recommended. However, use in specific patients who have massive uncontrolled bleeding and who do not respond to standard treatments and conventional blood components may still be a reasonable option, after potential benefits and risks of thrombotic complications are weighed. ${ }^{35}$

\section{Artificial oxygen carriers}

Hemoglobin substitutes may delay or reduce the exposure to allogeneic blood transfusions in trauma patients with acute blood loss. These products can replace the use of blood products during acute blood loss and, when combined with acute normovolemic hemodilution in the perioperative setting, could reduce the need for blood transfusions. Their use in critically ill patients could reduce the need for blood in patients requiring massive transfusions. There are 2 classes of hemoglobin substitutes: modified hemoglobins and the perfluorocarbons. ${ }^{36}$ The artificial hemoglobin solutions are either recombinant products or are derived from outdated human red blood cells or bovine hemoglobin. The potential advantages of hemoglobin substitutes include their availability without need for cross-matching, a long shelf life, the ability to store the products at room temperature and a reduced risk of disease transmission. ${ }^{36,37}$ Disadvantages include their relatively short half-life after administration (2448 hours), their interference with laboratory hemoglobin measurements, renal toxic effects, and adverse effects on vascular tone and blood pressure. The most recent generations of hemoglobin-based oxygen carriers have been modified to prevent rapid dissociation and short half-life, to avoid renal toxic effects and to reduce vasoconstriction by decreasing nitric oxide scavenging.

Despite the initial promise of diaspirin cross-linked hemoglobin in reducing the need for blood transfusion in cardiac and noncardiac surgery patients, ${ }^{38,39}$ a phase III randomized controlled trial involving trauma patients was stopped after an interim analysis showed higher mortality in the treatment group than in the control group $38 \% \mathrm{v}$. I $5 \%$ at 48 hours, $p=0.01 ; 46 \%$ v. $17 \%$ at 28 days, $p=$ $0.003) .{ }^{40}$ Although the underlying reason for the increased mortality is unclear, diaspirin cross-linked hemoglobin has been removed from the market. Other hemoglobin substi- tutes currently under investigation in phase III clinical trials involve the polymerization of blood cells, which is purported to attenuate vasoconstriction by reducing the risk of extravasation of the product and thereby limiting the scavenging of nitric oxide. ${ }^{37}$ These products include Polyheme, derived from outdated human blood, and Hemopure, derived from bovine hemoglobin. ${ }^{37}$ In phase II clinical trials, Polyheme was associated with a reduced need for blood transfusions in acute trauma and urgent surgery patients ${ }^{41}$ and was not associated with either systemic or pulmonary artery hypertension..$^{41,42} \mathrm{~A}$ pivotal phase III multicentre randomized controlled trial comparing Polyheme and standard crystalloid in prehospital resuscitation has recently been completed. Preliminary results reported by the manufacturer showed a decrease in the need for allogeneic blood transfusions in the Polyheme group, but the study failed to demonstrate non-inferiority in mortality as compared with standard treatment..$^{43}$ In phase II trials, Hemopure was associated with a reduction in the need for blood transfusions in patients undergoing elective orthopedic, ${ }^{44} \operatorname{cardiac}^{45}$ and noncardiac surgery. ${ }^{46}$ These findings have resulted in the product's approval in South Africa as an alternative to blood transfusions, and Hemopure is currently under review by the US Food and Drug Administration. The use of modified hemoglobin substitutes for the treatment of critically ill patients holds promise, but further research on the efficacy and safety of these products is required.

Perfluorocarbons are another class of hemoglobin substitute that are attractive because they transport both oxygen and carbon dioxide and can release oxygen to the tissues at a rate of about twice that of hemoglobin. Perfluorocarbons have the advantage of a long shelf life and no risk of transmission of blood-borne infections. However, because of the linear relation between the partial pressure of oxygen in blood and the oxygen content on perfluorocarbons, patients have to be given 100\% oxygen to provide effective oxygenation with this product. ${ }^{47}$ Such high inspired oxygen concentrations may induce acute lung injury. ${ }^{48}$ To date, perflubron (Oxygent) has been tested in combination with acute normovolemic hemodilution in a phase III trial involving patients undergoing elective noncardiac surgery. ${ }^{49}$ Overall, the patients who received perflubron received fewer allogeneic blood transfusions than the control patients. The full efficacy and safety profile of perfluorocarbon-based hemoglobin substitutes and their potential role in critically ill patients remains to be clarified through future studies.

\section{Blood recovery techniques}

Intraoperative red blood cell salvage is well recognized as a blood conservation strategy, ${ }^{50}$ but it has limited applicability in critically ill patients. Postoperative recovery and transfusion of blood from sterile surgical drains in cardiac surgery has shown only marginal reduction in transfusion requirements (relative risk $0.85,95 \% \mathrm{CI} 0.79-0.92$ )..$^{51}$ The feasibility and effectiveness of blood recovery techniques for other critically ill patients with acute blood loss are more limited. 


\section{Preventing subacute anemia in critically ill patients}

\section{Reducing blood loss associated with diagnostic testing}

Diagnostic testing is an important cause of blood loss in critically ill patients. ${ }^{1,2,52}$ Blood samples for diagnostic testing are commonly taken up to 24 times per day depending on patient illness acuity, ease of sampling and institutional practice. Indwelling central venous or arterial catheters contribute to increased sampling and blood loss because of the ease of sampling and because of the added requirement to discard the first few millilitres of infusate-blood mixture obtained when collecting blood from a fluid-infusing catheter. ${ }^{53-55}$ Studies from the I980s reported a mean blood loss per patient of $377 \mathrm{~mL} / \mathrm{d}$ in cardiothoracic ICUs, $240 \mathrm{~mL} / \mathrm{d}$ in general surgical ICUs and $4 \mathrm{I} .5 \mathrm{~mL} / \mathrm{d}$ in medical-surgical ICUs. ${ }^{53,56} \mathrm{~A}$ more recent study involving $\mathrm{II}_{3} 6$ patients in $\mathrm{I}_{45}$ western European ICUs found considerable blood loss through blood sampling, averaging $4 \mathrm{I} . \mathrm{I} \mathrm{mL} / \mathrm{d}$ per patient. ${ }^{2}$ In one study involving patients admitted to an ICU for more than 3 days, blood sampling accounted for $17 \%$ of the total blood loss. ${ }^{57}$ In 2 American studies, retrospective analysis identified that blood sampling accounted for $50 \%$ of the variation in the amount of red blood cells transfused. ${ }^{53,54}$ Not surprisingly, there appears to be a correlation between the severity of illness and both the number of blood draws and the total amount of blood sampled. 2,55 This increased blood loss through diagnostic testing places the most acutely ill patients at increased risk of anemia and exposes them to the attendant risks of blood transfusion.

Approaches to reduce iatrogenic blood loss in critically ill patients have included the use of small-volume (pediatric) blood collection tubes, the elimination or reduction of discarded blood when collecting blood from in-dwelling catheters and the altering of test-ordering behaviour. ${ }^{58}$

In 2 studies, the use of pediatric blood collection tubes reduced the volume by $37 \%{ }^{59}$ and $47 \%{ }^{60}$ respectively. In the first study, this was associated with a significant reduction in the proportion of patients requiring blood transfusions. ${ }^{59}$ The introduction of point-of-care testing could further reduce the volume of samples drawn. In addition to improved turnaround time and decreased personnel time, these bedside diagnostic tests often require less than $0.5 \mathrm{~mL}$. As the reliability and affordability of these technologies improve, they may become a valuable addition to blood conservation strategies.

Current technology already exists to eliminate the loss of discarded blood associated with blood sampling from indwelling catheters. Using a simple technique with a 3-way stopcock, the sample is drawn into a sterile syringe before taking the diagnostic samples and then reinfused into the patient. This strategy can reduce the mean amount of blood lost through blood sampling by $50 \% .{ }^{61}$ Similar reductions in blood loss associated with diagnostic testing have been demonstrated with the use of automated closed arterial systems. ${ }^{62-64}$ In most of the studies, ${ }^{61,63,64}$ eliminating the loss of discarded blood before diagnostic testing was associated with higher hemoglobin levels than levels in control patients, but none of the studies reported a reduction in blood transfusions. Although this may have been due to the small number of patients included in these studies, the amount of blood saved with these techniques alone may not be large enough to avoid the need for blood transfusion in critically ill patients.

\section{Erythropoietin}

Recombinant erythropoietin and other erythropoietin-receptor agonists are commonly used in patients who have chronic renal failure or cancer with bone marrow suppression, to increase hemoglobin levels and avoid the need for blood transfusions. Recombinant erythropoietin has also been used in critically ill patients for the same purpose. ${ }^{65}$ In the most recently published trial, Corwin and colleagues ${ }^{66}$ randomly assigned 1460 critically ill patients to receive either 40000 units of recombinant erythropoietin or placebo weekly for up to 3 weeks. The increase in hemoglobin concentration at day 29 was greater in the erythropoietin group than in the placebo group (mean 16 [SD 20] g/L v. I3 [SD I8] g/L, $p<0.00 \mathrm{I}$ ). However, in contrast to findings from previous trials, there was no difference between the 2 groups in the number of patients receiving blood transfusions or in the number of units transfused. This failure to affect transfusion requirements was attributed to the use of a more restrictive transfusion strategy. Overall, there was no significant difference in mortality at day 29 between the 2 groups (hazard ratio 0.79 , 95\% CI 0.56-I.IO). However, in a subgroup analysis, mortality was significantly lower among trauma patients in the erythropoietin group than among trauma patients receiving placebo. These findings from the subgroup analysis should be considered only as hypothesis generating, but because they are consistent with those from a previous large trial of erythropoietin in critically ill patients, further investigation is warranted. Importantly, there was a significant increase in the rate of deep vein thrombosis among patients receiving erythropoietin (hazard ratio I.4I, 95\% CI I.06-I.86).

In a systematic review of 9 studies, including the most recent study by Corwin and colleagues, ${ }^{66}$ Zarychanski and coauthors ${ }^{65}$ evaluated the use of erythropoietin in critically ill patients. They found a significant reduction in the odds of a patient receiving at least I red blood cell transfusion (odds ratio $0.73,95 \%$ CI $0.64-0.84$ ). ${ }^{65}$ There were no differences observed in mortality or occurrence of deep vein thrombosis. On the basis of these findings, erythropoietin appears effective in increasing hemoglobin levels in critically ill patients and may result in a reduced frequency of blood transfusions, but this latter effect is likely abrogated by the use of a restrictive transfusion strategy. In addition, the use of erythropoietin does not reduce mortality, and concerns remain regarding the potential increased risk for thrombotic events. ${ }^{65}$

\section{Restrictive red blood cell transfusion triggers}

The use of lower hemoglobin thresholds as restrictive transfusion triggers in critically ill patients has been extensively studied. Three large randomized controlled trials examined the effects of restrictive transfusion practices in adult, ${ }^{10}$ pediatric ${ }^{67}$ and neonatal patient populations. ${ }^{68}$ All 3 showed that restrictive transfusion practices reduced transfusion requirements without increasing morbidity or mortality. Because patients 
with acute bleeding were excluded in these studies, the results may not be generalizable to patients with acute blood loss.

In a randomized controlled trial involving 838 euvolemic critically ill adults whose hemoglobin concentration was below $90 \mathrm{~g} / \mathrm{L}$, Hébert and colleagues ${ }^{10}$ randomly assigned patients to be managed with either a restrictive transfusion strategy (target hemoglobin concentration 70-90 g/L with a hemoglobin transfusion threshold of $70 \mathrm{~g} / \mathrm{L}$ ) or a liberal transfusion strategy (target hemoglobin concentration Ioo$120 \mathrm{~g} / \mathrm{L}$ with a hemoglobin transfusion threshold of $100 \mathrm{~g} / \mathrm{L}$ ). Compared with patients in the liberal strategy arm, those in the restrictive strategy arm had a lower mean hemoglobin level (85 [SD 7] v. I07 [SD 7] g/L, $p<0.01$ ), received fewer transfusions (2.6 [SD 4.I] v. 5.6 [SD 5.3] units per patient, $p<0.0 \mathrm{I}$ ) and had a lower mortality at 30 days (I8.7\% v. $23.3 \%, p=0 . \mathrm{II}$ ). The results from this trial demonstrated that a restrictive transfusion strategy would reduce transfusion requirements and would be as safe as, and possibly better than, a more liberal strategy for critically ill adults. ${ }^{10}$ From subgroup analyses of the results of this study, the findings appear to be consistent across most patient groups, with the possible exception of patients with cardiac disease,${ }^{10}$ the only subgroup that did not show improved survival with the restrictive transfusion strategy. The results of a large retrospective observational study suggested that transfusion at higher hemoglobin thresholds may be beneficial in patients with acute myocardial infarction, ${ }^{69}$ but this was not supported in a subsequent study, in which transfusion was associated with increased mortality. ${ }^{70}$ Further studies are required in this patient group to determine whether a lower hemoglobin transfusion trigger is safe.

In a recently published randomized controlled trial involving 637 pediatric ICU patients, Lacroix and colleagues ${ }^{67}$ found that a hemoglobin threshold of $70 \mathrm{~g} / \mathrm{L}$, compared with a more liberal threshold of $95 \mathrm{~g} / \mathrm{L}$, reduced transfusion requirements by $44 \%$ (0.9 [SD 2.6] v. I.7 [SD 2.2] units per patient, $p<$ $0.00 \mathrm{I})$ without differences in mortality or in new or progressive multiple-organ dysfunction between the 2 groups. Similar results were found in the PINT (Premature Infants in Need of Transfusion) study, which involved 45I premature infants ( $<3$ I weeks' gestation) with extremely low birth weights $(<\mathrm{I000} g) .{ }^{68}$ In this study, hemoglobin thresholds varied according to age (days), method of blood sampling (capillary v. central catheter) and need for respiratory support. The differences in the hemoglobin thresholds for the restrictive and liberal transfusion strategies were between $9 \mathrm{~g} / \mathrm{L}$ and $20 \mathrm{~g} / \mathrm{L}$. Compared with the infants in the liberal strategy arm, those in the restrictive strategy arm had a lower mean hemoglobin level and a trend toward decreased number of transfusions (4.9 [SD 4.2] v. 5.7 [SD 5.0] per infant, $p=0.07$ ). Infants in the restrictive strategy arm were exposed to fewer red blood cell donors (2.I [SD 2.0] v. 2.6 [SD 2.7], $p=0.035$ ). The 2 groups did not differ in the primary combined outcome of death or survival with bronchopulmonary dysplasia, severe retinopathy of prematurity or brain injury. Similarly, in a previous single-centre study involving roo preterm infants, Bel and colleagues ${ }^{71}$ found no differences in survival, patent ductus arteriosis, retinopathy or bronchopulmonary dysplasia between the study groups, but they did find an increase in apneic and neurologic events in the restrictive strategy group.

Taken together, these 3 multicentre studies provide strong evidence that a restrictive transfusion strategy with a lowered hemoglobin threshold is safe $\mathrm{e}^{10,67,68}$ and is possibly superior to a liberal transfusion strategy with a higher hemoglobin threshold. ${ }^{72}$ In general, a hemoglobin threshold of $70 \mathrm{~g} / \mathrm{L}$ appears to be appropriate for critically ill adult and pediatric patients, and previous notions of higher thresholds should be abandoned in most patient groups.

\section{Conclusion}

Blood transfusions are commonly administered to critically ill patients. Although they can be life-saving, they are also associated with adverse events. Reducing blood loss and the need for blood transfusions and improving the appropriateness of blood transfusion are important quality-of-care issues for critically ill patients. A variety of strategies exist to reduce the need for blood transfusions in critically ill patients. They include the use of hemostatic drugs, erythropoietin to stimulate red blood cell production and artificial blood substitutes. However, the most effective blood conservation strategies remain the simplest and likely least costly. The reduction of blood loss associated with diagnostic testing seems a logical, proximate intervention and may reduce the burden of anemia among critically ill patients. The adoption of a lower hemoglobin threshold as a restrictive transfusion practice is the only intervention that has been evaluated in large clinical trials and has been found to reduce transfusion requirements. As recently reviewed, even simple interventions such as audit programs, educational programs and reminders can be effective in changing physician transfusion practice $^{73,74}$ and therefore could be used to increase compliance with restrictive transfusion practices involving lower hemoglobin thresholds. ${ }^{75,76}$ Additional pharmacological and mechanical therapies to reduce blood loss and the transfusion of blood products may yet prove to be beneficial, but the effectiveness and safety of these measures still need to be proven.

This article has been peer reviewed.

Competing interests: None declared for Lauralynn McIntyre or Robert Fowler. Alan Tinmouth has received consultancy fees from Bayer, Inc., and NovoNordisk, Inc.

Contributors: All of the authors contributed to the conception, design and drafting of the article and provided final approval of the version to be published.

Acknowledgements: Alan Tinmouth is supported by a Canadian Blood Services/ Canadian Institutes of Health Research New Investigator Award. Robert Fowler is a Career Scientist of the Ontario Ministry of Health and Long-term Care.

\section{REFERENCES}

I. Corwin HL, Gettinger A, Pearl RG, et al. The CRIT Study: anemia and blood transfusion in the critically ill - current clinical practice in the United States. Crit Care Med 2004;32:39-52.

2. Vincent JL, Baron JF, Reinhart K, et al. Anemia and blood transfusion in critically ill patients. JAMA 2002;288:I499-507.

3. Blajchman MA, Klein HG. Looking back in anger: retrospection in the face of a paradigm shift. Transfus Med Rev I997;II:I-5.

4. Tinmouth AT, Fergusson DA, Yee IC, et al; ABLE Investigators and Canadian Critical Care Trials Group. Clinical consequences of red cell storage in the critically ill. Transfusion 2006;46:2014-27. 
5. Ronco JJ, Fenwick JC, Tweeddale MG. Does increasing oxygen delivery improve outcome in the critically ill? No. Crit Care Clin 1996;12:645-59.

6. Hébert PC, Hu LQ, Biro GP. Review of physiologic mechanisms in response to anemia. CMAJ I997;156:S27-40.

7. Rixen D, Raum M, Bouillon B, et al. Base deficit development and its prognostic significance in posttrauma critical illness: an analysis by the trauma registry of the Deutsche Gesellschaft für unfallchirurgie. Shock 200I;15:83-9.

8. Kleinman S, Chan P, Robillard P. Risks associated with transfusion of cellular blood components in canada. Transfus Med Rev 2003;17:120-62.

9. Popovsky MA, editor. Transfusion reactions. 2 nd ed. Bethesda (MD): AABB Press; 2001.

Io. Hébert PC, Wells G, Blajchman MA, et al. A multicenter, randomized, controlled clinical trial of transfusion requirements in critical care. Transfusion Requirements in Critical Care Investigators, Canadian Critical Care Trials Group. N Engl) Med I999;340:409-I7.

II. Chang H, Hall GA, Geerts WH, et al. Allogeneic red blood cell transfusion is an independent risk factor for the development of postoperative bacterial infection. Vox Sang 2000;78:13-8.

I2. Vamvakas EC, Carven JH. Transfusion and postoperative pneumonia in coronary artery bypass graft surgery: effect of the length of storage of transfused red cells Transfusion I999;39:70I-IO.

I3. Fergusson D, Khanna MP, Tinmouth A, et al. Transfusion of leukoreduced red blood cells may decrease postoperative infections: two meta-analyses of randomized controlled trials. Can J Anaesth 2004;51:417-24.

I4. Hardy JF, de Moerloose P, Samama CM. The coagulopathy of massive transfusion. Vox Sang 2005;89:123-7.

15. Henry DA, Carless P, Moxey A, et al. Anti-fibrinolytic use for minimising perioperative allogeneic blood transfusion [review]. Cochrane Database Syst Rev 2007;(4) CDoor886.

I6. Mangano DT, Tudor IC, Dietzel C. The risk associated with aprotinin in cardiac surgery. N Engl J Med 2006;354:353-65.

17. FDA requests marketing suspension of Trasylol [press release]. Rockville (MD) US Food and Drug Administration; 2007 Nov 5. Available: www.fda.gov/bbs /topics/NEWS/2007/NEWo1738.html (accessed 2007 Nov 13).

I8. Henry DA, O'Connell DL. Effects of fibrinolytic inhibitors on mortality from upper gastrointestinal haemorrhage. BMJ I989;298:1142-6.

I9. Auer LM, Marth E, Heppner F, et al. Proteolytic enzyme activity in patients with severe head injury and the effect of a proteinase inhibitor. Acta Neurochir (Wien) I979;49:207-I7

20. McMichan JC, Rosengarten DS, Philipp E. Prophylaxis of post-traumatic pulmonary insufficiency by protease-inhibitor therapy with aprotinin: a clinical study. Circ Shock 1982;9:107-16.

2I. Coats T, Roberts I, Shakur H. Antifibrinolytic drugs for acute traumatic injury [review]. Cochrane Database Syst Rev 2004;(4):CDoo4806.

22. Protocol 05PRT/I: the CRASH-2 (Clinical Randomization of an Anti-fibrinolytic in Significant Haemorrhage) trial [Lancet protocol review]. Available: www.thelancet com/journals/lancet/misc/protocol/05PRT-I (accesed 2007 Oct 22).

23. Mannucci PM. Hemostatic drugs. N Engl J Med I $998 ; 339: 245-53$

24. Mannucci PM. Desmopressin (DDAVP) in the treatment of bleeding disorders: the first 20 years. Blood 1997;90:2515-2I.

25. Grant MJ, Huether SE, Witte MK. Effect of red blood cell transfusion on oxygen consumption in the anemic pediatric patient. Pediatr Crit Care Med 2003;4:459-64.

26. Levi $M$, Peters $M$, Buller HR. Efficacy and safety of recombinant factor VIIa for treatment of severe bleeding: a systematic review. Crit Care Med 2005;33:883-90.

27. Boffard KD, Riou B, Warren B, et al. Recombinant factor VIIa as adjunctive therapy for bleeding control in severely injured trauma patients: two parallel randomized, placebo-controlled, double-blind clinical trials. JTrauma 2005;59:8-I5.

28. Bosch J, Thabut D, Bendtsen F, et al. Recombinant factor VIIa for upper gastrointestinal bleeding in patients with cirrhosis: a randomized, double-blind trial. Gas troenterology 2004; I27:II23-30.

29. Diprose P, Herbertson MJ, O'Shaughnessy D, et al. Activated recombinant factor VII after cardiopulmonary bypass reduces allogeneic transfusion in complex noncoronary cardiac surgery: randomized double-blind placebo-controlled pilot study. BrJ Anaesth 2005;95:596-602.

30. Lodge JP, Jonas S, Oussoultzoglou E, et al. Recombinant coagulation factor VIIa in major liver resection: a randomized, placebo-controlled, double-blind clinical trial. Anesthesiology 2005;102:260-75.

31. Planinsic RM, van der Meer MJ, Testa G, et al. Safety and efficacy of a single bolus administration of recombinant factor VIIa in liver transplantation due to chronic liver disease. Liver Transpl 2005; II:895-900.

32. Mayer SA, Brun NC, Begtrup K, et al. Recombinant activated factor VII for acute intracerebral hemorrhage. N Engl J Med 2005;352:777-85

33. Stanworth SJ, Birchall J, Doree CJ, et al. Recombinant factor VIIa for the prevention and treatment of bleeding in patients without haemophilia [review]. Cochrane Database Syst Rev 2007; (2):CDoo50II.

34. Phase 3 stroke trial shows that NovoSeven reduces bleeding in the brain, but does not improve long-term clinical outcomes. Bagsvaerd (Denmark): Novo Nordisk; $2007 \mathrm{Feb}$ 26. Available: www.novonordisk.com/press/sea/sea.asp?NewsTypeGuid=\&sShow NewsItemGUID=ocfcr2oc-for $3-4$ ad6-9130-55227465eze8\&sShowLanguageCode=en -GB (accessed 2007 Nov 22).

35. Goodnough LT, Lublin DM, Zhang L, et al. Transfusion medicine service policies for recombinant factor VIIa administration. Transfusion 2004;44:1325-3I.

36. Spahn DR, Kocian R. Artificial $\mathrm{O}_{2}$ carriers: status in 2005. Curr Pharm Des 2005 II:4099-II4.
37. Moore FA, Moore EE, Sauaia A. Blood transfusion. An independent risk factor for postinjury multiple organ failure. Arch Surg I997;132:620-4

38. Lamy ML, Daily EK, Brichant JF, et al. Randomized trial of diaspirin cross-linked hemoglobin solution as an alternative to blood transfusion after cardiac surgery. The DCLHb Cardiac Surgery Trial Collaborative Group. Anesthesiology 2000;92:646-56.

39. Schubert A, Przybelski RJ, Eidt JF, et al. Diaspirin-crosslinked hemoglobin reduces blood transfusion in noncardiac surgery: a multicenter, randomized, controlled, double-blinded trial. Anesth Analg 2003;97:323-32.

40. Sloan EP, Koenigsberg M, Gens D, et al. Diaspirin cross-linked hemoglobin (DCLHb) in the treatment of severe traumatic hemorrhagic shock: a randomized controlled efficacy trial. JAMA I999;282:1857-64.

4I. Gould SA, Moore EE, Hoyt DB, et al. The first randomized trial of human polymerized hemoglobin as a blood substitute in acute trauma and emergent surgery. J Am Coll Surg 1998;187:113-20.

42. Johnson JL, Moore EE, Offner PJ, et al. Resuscitation of the injured patient with polymerized stroma-free hemoglobin does not produce systemic or pulmonary hypertension. Am J Surg 1998;176:612-7.

43. Northfield Laboratories reports results of pivotal phase III trauma study [press release]. Evanston (IL): Northfield Laboratories Inc.; 2007 May 23. Available: http: //phx.corporate-ir.net/phoenix.zhtml?c=91374\&p=irol-newsArticle\&ID=100595I\& highlight $=$ (accessed 2007 Oct 22)

44. Jahr JS. A novel blood substitute: results of a pivotal trial in orthopoedic surgery patients. Crit Care Med 2001;29:S243.

45. Levy JH, Goodnough LT, Greilich PE, et al. Polymerized bovine hemoglobin solution as a replacement for allogeneic red blood cell transfusion after cardiac surgery: results of a randomized, double-blind trial. J Thorac Cardiovasc Surg 2002;124:35-42.

46. LaMuraglia GM, O'Hara PJ, Baker WH, et al. The reduction of the allogenic transfusion requirement in aortic surgery with a hemoglobin-based solution. J Vasc Surg 2000;31:299-308.

47. Tremblay LN, Rizoli SB, Brenneman FD. Advances in fluid resuscitation of hemorrhagic shock. Can J Surg 200I;44:172-9.

48. Jenkinson SG. Oxygen toxicity. New Horiz I993;I:504-II.

49. Spahn DR, Waschke KF, Standl T, et al; European Perflubron Emulsion in NonCardiac Surgery Study Group. Use of perflubron emulsion to decrease allogeneic blood transfusion in high-blood-loss non-cardiac surgery: results of a European phase 3 study. Anesthesiology 2002;97:1338-49

50. Goodnough LT, Brecher ME, Kanter MH, et al. Transfusion medicine. Second of two parts - blood conservation. N Engl J Med I999;340:525-33.

5I. Huet C, Salmi LR, Fergusson D, et al. A meta-analysis of the effectiveness of cell salvage to minimize perioperative allogeneic blood transfusion in cardiac and orthopedic surgery. International Study of Perioperative Transfusion (ISPOT) Investigators. Anesth Analg 1999;89:86I-9.

52. Fowler RA, Berenson M. Blood conservation in the intensive care unit. Crit Care Med 2003;3I:S7I5-20.

53. Smoller BR, Kruskall MS. Phlebotomy for diagnostic laboratory tests in adults. Pattern of use and effect on transfusion requirements. N Engl J Med I986;314:1233-5.

54. Corwin HL, Parsonnet KC, Gettinger A. RBC transfusion in the ICU. Is there a reason? Chest I995; I08:767-7I.

55. Zimmerman JE, Seneff MG, Sun X, et al. Evaluating laboratory usage in the intensive care unit: patient and institutional characteristics that influence frequency of blood sampling. Crit Care Med I997;25:737-48.

56. Henry ML, Garner WL, Fabri PJ. Iatrogenic anemia. Am J Surg I986;151:362-3.

57. Von Ahsen N, Muller C, Serke S, et al. Important role of nondiagnostic blood loss and blunted erythropoietic response in the anemia of medical intensive care patients. Crit Care Med I999;27:2630-9.

58. Corwin HL. Blood conservation in the critically ill patient. Anesthesiol Clin North America 2005;23:363-72.

59. Arkin S, Blei F, Fetten J, et al. Human coagulation factor FVIIa (recombinant) in the management of limb-threatening bleeds unresponsive to alternative therapies: results from the NovoSeven emergency-use programme in patients with severe haemophilia or with acquired inhibitors. Blood Coagul Fibrinolysis 2000;II:255-9.

6o. Smoller BR, Kruskall MS, Horowitz GL. Reducing adult phlebotomy blood loss with the use of pediatric-sized blood collection tubes. Am J Clin Pathol 1989;9I:70I-3

6r. Gleason E, Grossman S, Campbell C. Minimizing diagnostic blood loss in critically ill patients. Am J Crit Care I992;1:85-90.

62. MacIsaac CM, Presneill JJ, Boyce CA, et al. The influence of a blood conserving de vice on anaemia in intensive care patients. Anaesth Intensive Care 2003;31:653-7.

63. Peruzzi WT, Parker MA, Lichtenthal PR, et al. A clinical evaluation of a blood conservation device in medical intensive care unit patients. Crit Care Med I993;2I:50I-6.

64. Silver MJ, Li YH, Gragg LA, et al. Reduction of blood loss from diagnostic sampling in critically ill patients using a blood-conserving arterial line system. Chest I993; I04:I7II-5

65. Zarychanski R, Turgeon AF, McIntyre L, et al. Erythropoietin-receptor agonists in critically ill patients: a meta-analysis of randomized controlled trials. CMAJ 2007 I77:725-34

66. Corwin HL, Gettinger A, Fabian TC, et al. Efficacy and safety of epoetin alfa in critically ill patients. N EngI J Med 2007;357:965-76.

67. Lacroix J, Hébert PC, Hutchison JS, et al. Transfusion strategies for patients in pediatric intensive care units. NEngl JMed 2007;356:I609-I9.

68. Kirpalani H, Whyte RK, Andersen C, et al. The Premature Infants in Need of Transfusion (PINT) study: a randomized, controlled trial of a restrictive (low) versus liberal (high) transfusion threshold for extremely low birth weight infants. J Pediatr 2006;I49:30I-7.

69. Wu WC, Rathore SS, Wang Y, et al. Blood transfusion in elderly patients with acute 
myocardial infarction. N Engl JMed 200I;345:1230-6

70. Rao SV, Jollis JG, Harrington RA, et al. Relationship of blood transfusion and clinical outcomes in patients with acute coronary syndromes. JAMA 2004;292:1555-62.

7I. Bell EF, Strauss RG, Widness JA, et al. Randomized trial of liberal versus restrictive guidelines for red blood cell transfusion in preterm infants. Pediatrics 2005;II5: I685-9r.

72. Hébert PC, Wells G, Tweeddale M, et al. Does transfusion practice affect mortality in critically ill patients? Transfusion Requirements in Critical Care (TRICC) Investigators and the Canadian Critical Care Trials Group. Am J Respir Crit Care Med I997; $155: 1618-23$

73. Tinmouth A, MacDougall L, Fergusson D, et al. Reducing the amount of blood transfused: a systematic review of behavioral interventions to change physicians transfusion practices. Arch Intern Med 2005; I65:845-52.

74. Wilson K, MacDougall L, Fergusson D, et al. The effectiveness of interventions to reduce physician's levels of inappropriate transfusion: what can be learned from a systematic review of the literature. Transfusion 2002;42:1224-9.

75. Walsh TS, McArdle F, McLellan SA, et al. Does the storage time of transfused red blood cells influence regional or global indexes of tissue oxygenation in anemic critically ill patients? Crit Care Med 2004;32:364-7I.

76. French CJ, Bellomo R, Finfer SR, et al. Appropriateness of red blood cell transfusion in Australasian intensive care practice. Med J Aust 2002;177:548-5I.

Correspondence to: Dr. Alan T. Tinmouth, Ottawa Hospital, 50I Smyth Rd., Box 20I, Ottawa ON KIH 8L6; fax 6I3 739-6266; atinmouth@ohri.ca
Appendix 1: Search strategy used to identify studies of blood conservation strategies

- MEDLINE (articles published from 1966 to August 2007) and the Cochrane Database of Systematic Reviews (second quarter of 2007) were searched to identify relevant articles for inclusion in the review

- Search terms included "intensive care," "critical care," "trauma," "blood conservation," "phlebotomy," "erythrocyte transfusion," "erythropoietin,"

"antifibrinolytic agents," "deamino arginine vasopressin," "factor VIla," "randomized controlled trial," "systematic review" and "guideline"

- Search terms were combined using Boolean logic (and, or)

- Studies of blood conservation strategies used in critical care populations were selected; studies of other strategies not specifically used in critical care populations were also selected if the strategy was widely used (i.e., in other medical or surgical specialties) and had potential future applicability in critical care settings

\section{(n) What do more than 3,000 effective physician leaders have in common?}

\section{They have benefited from the CMA PMI (Physician Manager Institute)!}

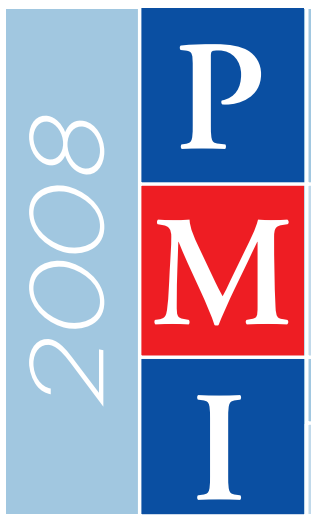

\author{
PMI I: Effective management \\ \& leadership /
}

PMI II: High-performance feams

PMI III: Negotiation and conflict /
PMI IV: Change management

PMI III: Negotiation and conflict
PMI IV: Change management

PMI V: Strategic thinking

Elective V: Disruptive physician

behaviour
2-4 Mar. / 5-7 Mar.

15-17 June / 18-20 June

19-21 Oct. / 22-24 Oct.

11-13 May / 14-16 May

21-23 Sept. / 24-26 Sept.

9-11 Nov. / 12-14 Nov.

28-30 Nov.

23-24 May
Victoria, BC

Ottawa, Ont.

Toronto, Ont.

Niagara-on-the-Lake, Ont.

Montréal, Que.

Vancouver, BC

Vancouver, BC

Toronto, Ont.

In-house PMI also available: On-site courses for health leaders.

Please visit cma.ca/leadership for details, email Professional_Development@cma.ca

or contact us at $800663-7336 \times 2319$

\section{ASSOCIATION \\ MÉDICALE \\ CANADIENNE}

CANADIAN

MEDICAL

ASSOCIATION 